\title{
ELEMENTOS ICONOGRÁFICOS Y EMBLEMÁTICOS EN LOS EPIGRAMAS DE INTERIÁN DE AYALA
}

\author{
ICONOGRAPHIC AND EMBLEMATIC ELEMENTS IN THE EPIGRAMS \\ OF INTERIÁN DE AYALA
}

Marcos Ruiz Sánchez, María Ruiz Sánchez

Universidad de Murcia

ABSTRACT • The Neo-Latin poetry of Interián conveys the interest of the author of the Pictor Christianus in iconography and emblems. This interest is expressed in all of his compositions. But it is in the epigrams in particular where this side of the Mercedarian writer can be best observed.

KEYWORDS: Juan Interián de Ayala; Epigrams; Iconography; Emblems.

RESUMEN • La poesía neolatina de Interián refleja el interés del autor del Pictor Christianus por la iconografía y los emblemas. Este interés se manifiesta en todas sus composiciones. Pero es sobre todo en los epigramas donde mejor puede observarse esta faceta del escritor mercedario.

PALABRAS CLAVES: Juan Interián de Ayala; Epigramas; Iconografía; Emblemas. 


\section{LA POESÍA DE INTERIÁN Y LA CULTURA VISUAL DE SU ÉPOCA}

El propósito de este artículo es mostrar la importancia del componente iconográfico y emblemático en la poesía neolatina de Juan Interián de Ayala (1656-1730).

Nació y murió este autor en Madrid. En 1672 ingresó en la orden de los mercedarios. Se doctoró en Artes y Teología en la Universidad de Salamanca y obtuvo en esa misma universidad las cátedras de Artes, Elocuencia y Lenguas Sagradas. Fue el primer ocupante de la silla $E$ de la Real Academia Española. ${ }^{1}$ Destacó también como predicador, teólogo y escritor. En 1729 Francisco de Ribera, perteneciente a su misma orden, publica en un volumen titulado Humaniores atque amoeniores ad Musas excursus: siue Opuscula poetica quae quondam lusit aut pinxit R.A.P.M. Fr. Ioannes Interian de Ayala muchas de las composiciones de Interián, incluyendo algunos poemas de la obra Pictor Christianus eruditus, que vería la luz en $1730 .^{2}$ Esta última obra es un tratado sobre las imágenes sacras realizado con la finalidad de corregir los errores que acostumbraban a cometer los pintores al representar las temas religiosos.

La importancia de la iconografía y la emblemática es evidente en toda la obra poética de Interián y está en estrecha relación con su labor como predicador y con los intereses puestos de manifiesto en el Pictor Christianus. No puede, pues, extrañarnos que el elemento iconográfico y emblemático sea una de las claves de la obra poética del autor.

Esta faceta de la obra de Interián permite comprobar, por una parte, su continuidad con la época anterior y con la cultura visual de los siglos XVI-XVIII y por otra, su originalidad en este terreno.

\section{LAS IMÁGENES DE LOS SANTOS Y LOS ICONES PHILOSOPHORUM}

La relación entre poesía y emblemática se da en toda la obra poética de Interián, pero es especialmente visible en los epigramas. Entre los textos incluidos en la obra editada por Ribera, hay una serie de epigramas en alabanza de los santos que también se encuentran en el Pictor Christianus. Baste citar, como ejemplo, el siguiente epigrama sobre san Benito que se arroja desnudo a una zarza para evitar la tentación de la lujuria (Ribera, 1729: 117-118):3

\section{S. BENEDICTI ${ }^{4}$ \\ Quid te spinetis, iunenis sanctissime, uoluis, Lancinat et tenerum sentis acerba latus? Iam scio: perstrinxit purum mala flamma cruorem; Hoc nisi quam fuso, perdere posse, negas.}

1. La historiografía ha atribuido al marqués de Villena el protagonismo en la fundación en 1713 de la Real Academia Española y ha dejado en el anonimato a otros cofundadores, entre los que se encuentra Juan Interián de Ayala (Mestre Sanchis, 2002: 282).

2. De la obra se hicieron otras tres ediciones: en 1782 y 1883 en castellano y en 1854 en italiano. Sobre El Pintor cristiano y erudito puede consultarse Argelich Gutiérrez (2013 y 2014).

3. En las ediciones del Pictor Christianus en el v. 2 figura Atque latus tenerum sentis acerbus arat? (Interián, 1730: 16; 1782, I: 41).

4. Cf. sobre este epigrama Ruiz Sánchez (2013: 80). Un epigrama latino sobre el mismo tema puede leerse en Musa canicularis (LXVII) de Giusseppe Silos (1601-1674), obra que responde a la tradición de los icones poéticos (1658: 218-219). 
Vicisti: extincta est flamma haec, quo canduit igne; Seque uidens uictam, protinus erubuit.

Quam bene! Nam mollis spinas dea Cypris abhorret. Et fugit armatos cautior illa rubos.

[¿Por qué, joven santísimo, te revuelcas entre los zarzales y las acerbas espinas desgarran tu costado? Ya lo sé: se apoderó de tu sangre pura una llama dañina, de la que no podías deshacerte sino derramándola. Venciste: apagada está la llama con el fuego con el que ardió. Viéndose vencida, al punto enrojeció. ¡Bien está! Pues la divina Venus en su blandura aborrece las espinas y huye precavida de las armadas zarzas. $]^{5}$

Otro grupo de epigramas donde se manifiesta el mismo tipo de interés por parte del autor es la serie titulada Icones philosophorum. Se trata de un conjunto de doce composiciones dedicadas a los filósofos griegos. Corresponde a la tradición poética iniciada con los Césares de Ausonio, autor muy del agrado de Interián. En el siglo XVII el género de los icones había sido cultivado por Tesauro y otros muchos autores y admitía tanto la temática profana de reyes, emperadores y otros personajes ilustres, como las imágenes religiosas de santos o papas.

Todos los epigramas de esta serie sobre los filósofos constan de ocho versos, lo que sin duda es intencionado. Es también la extensión predominante en los poemas en elogio de los santos, aunque en estos la extensión puede variar entre 6 y 8 versos. Quizás la razón de esta restricción relativa a la extensión sea que tales composiciones estaban pensadas para acompañar a una imagen. La forma métrica del género era habitualmente el dístico elegiaco, que permite explotar la dualidad métrica dentro del dístico y los paralelismos entre las distintas secciones del texto. Junto a las limitaciones exteriores hay que tener, pues, en cuenta la existencia de un desarrollo interno, por el que primero se ofrece lo esencial de la visión del mundo del personaje y después la lección que puede extraerse de aquella, o bien primero la parte positiva y aceptada y finalmente las objeciones.

Aunque los epigramas en cuestión están llenos de alusiones que remiten sobre todo a Diógenes Laercio y otras fuentes antiguas, contienen también elementos relacionados con la tradición poética clásica y neolatina. Un ejemplo es el primer epigrama de la serie, dedicado a Pitágoras (Ribera, 1729: 127):

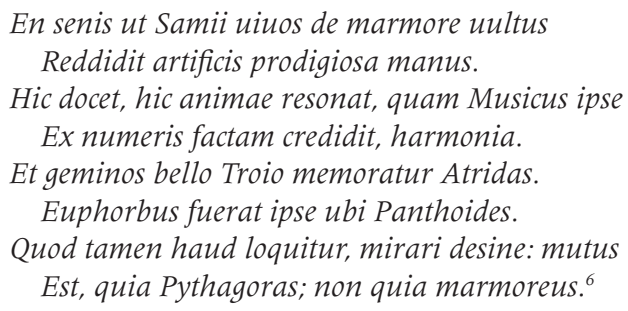

[La mano del artista, hacedora de prodigios, ha hecho renacer del mármol el vivo rostro del anciano de Samos. Aquí sigue enseñando, sigue resonando, la armonía del alma, que él, aficionado a la música como era, creyó que estaba compuesta de números, Y recuerda a los dos atridas en la guerra de Troya, cuando él mismo fue Euforbo, el hijo de Panto. En cuanto a que no hable, no te extrañe. La razón de que guarde silencio, no es que sea de mármol, sino que es Pitágoras].

5. Todas las traducciones de este trabajo son nuestras.

6. Las fuentes son Diógenes Laercio (8, 21), Ovidio (Met. 15, 160-162) y Aulo Gelio (1, 9).

IMAGO, NÚM. 10, 2018, 217-228 
El tema de la estatua silenciosa de Pitágoras desarrollado en este primer epigrama cuenta con una larga tradición, que arranca de la Anthologia Palatina. Andrea Navagero (14831529) en el poema De Pythagorae simulacro de su obra Lusus (1973: 44) lo había recreado en la literatura neolatina y Emanuele Tesauro (1591-1677) lo había aplicado a san Bruno, incorporándolo así a la tradición de los icones sagrados (1637: 49). Pierre-Juste Sautel (16131662) en Annus sacer poeticus, una obra que puede considerarse afín a la misma tradición, imitó el tema en dos epigramas referentes el uno a san Luis Gonzaga (1665, I: 238) y el otro a san Bruno (1665, II: 127), en los que combina la influencia de Navagero con la de Tesauro. Más adelante el humanista canario Juan de Iriarte (1702-1771) lo aplicará de nuevo a san Bruno en un ciclo de tres epigramas (1774: 118-119). ${ }^{7}$

El epigrama de Interián se sitúa en la tradición de los icones, pero vuelve el poema a su origen, aplicándolo a Pitágoras. Novedoso es el contraste entre el tema de la estatua silenciosa y el de la música del universo.

También tradicional es el contraste entre Demócrito y Heráclito, que subyace en el tratamiento que Interián hace de ambos filósofos (Ribera, 1729: 129-130):

\section{DEMOCRITI}

Sparge iocos, petulans ride; mortalia cuncta Quam lacrymis risu sunt mage digna tuo.

Sed uidesis, num se ridendum iure propinet, Ridiculis quisquis miscet acerba iocis?

Interea innumeros iuuenis, cui haud sufficit unus, Quod nondum mundos possit habere, dolet:

Ridiculos orbes suspirans, futilis en uox, Qua, non digna magis risibus ulla tuis. ${ }^{8}$

[Esparce las chanzas; ríe petulante. Las cosas mortales son todas más dignas de tu risa que de las lágrimas. Pero atiende: ¿no se arriesga a ser con razón objeto de burla, quienquiera que mezcla cosas amargas con ridículas chanzas? Entretanto el joven al que no basta un solo mundo se lamenta de que haya innumerables mundos, por no poderlos poseer aún, suspirando por ridículos orbes. He aquí una sentencia vana donde las haya; ninguna más digna de tus risas.]

\section{HERACLITI}

Ignoscenda tibi est ueniabilis ira doloris; Cui sic res hominum flere subinde placet.

Est ne tamen, rogo, fletu miserabilis ipso Sponte sua quisquis cogitur esse miser?

Si in speciem id praestas, fletor moestissime, cur non Ridendas lacrymas suspicer esse tuas?

Sic quoque pars hominum falsa sub imagine luctus Sat bene nota sibi gaudia tecta gemit.

[Debe disculpársete la ira del dolor digno de perdón, a ti, a quien le place llorar la realidad humana. ¿No es, sin embargo, pregunto, desdichado a causa de su propio llanto quienquiera que es forzado a ser desgraciado por iniciativa propia? Si haces esto para aparentar, ¿por qué no voy a sospechar, llorón tristísimo, que son dignas de risa tus lágrimas? Así

7. Para el tratamiento del tópico de la estatua silenciosa en la literatura neolatina véase Ruiz Sánchez (2016).

8. Las fuentes son Diógenes Laercio (9,9), Juvenal (Sat. 10, 33-35), Valerio Máximo (8, 14, ext.2) y Cicerón (Ac. 2, $17,55)$. 
también parte de los hombres gime bajo la falsa imagen del luto, lo que son gozos ocultos bien conocidos de su corazón].

La contraposición de Heráclito y Demócrito se encontraba ya en el epigrama griego (A.P. IX 148). En el Renacimiento el tema entró a formar parte desde Alciato de la tradición emblemática. Alciato desarrolla el tema en el emblema CLI (In uitam humanam), que constituye una versión del epigrama griego (2016: 164):

Plus solito humanae nunc defle incommoda uitae Heraclite: scatet pluribus illa malis.

Tu rursus, si quando alias, extolle cachinnum Democrite: illa magis ludicra facta fuit.

Interea haec cernens meditor, qua denique tecum

Fine fleam, aut tecum quomodo splene iocer.

[Llora ahora, Heráclito, más de lo acostumbrado las incomodidades de la vida humana, pues está llena de muchos males. Tú, por el contrario, Demócrito, levanta más que antes tus carcajadas: pues se ha hecho más chistosa. Entretanto, contemplando tales cosas, medito cuándo terminaré de llorar con uno o cómo me partiré de risa con el otro.]

Nicolas Bourbon (Borbonius, 1503- c. 1551), el poeta neolatino francés del siglo XVI, adaptó también el mismo epigrama griego al latín (1533: s.p.):

II, 96, E graeco.

Hanc potius uitam Heraclite, haec tempora defle, Haec uita est lachrymis quam tua, digna magis:

Hanc potius uitam, haec, Democrite tempora ride, Haec uita est risu, quam tua, digna magis:

Vos ego contemplans, dubito qui fiet, ut ambos Hunc imiter ridens, hunc imiter lachrymans.

[Heráclito, llora esta vida, llora esta época: esta vida es más digna de tus lágrimas que la tuya. Demócrito, ríete de esta vida, ríete de esta época: esta vida es más digna de risa que la tuya. Yo, contemplándoos, dudo cómo podré imitar a ambos, a uno riendo, a otro llorando.]

El tema reaparece en diversos epigramas neolatinos. Por ejemplo, el poeta francés Jean Visagier (Vulteius, 1510-1542) le dedicó dos epigramas (1537: 41-42):

\section{135, Ad Nicol. Frizonum.}

Tempora cur deflens Heraclitus sua planxit? Crimina criminibus, quod mala iuncta malis.

Tempora cur ridens risit Democritus olim? Quod uitio uirtus commaculata foret.

O si nunc hominum mores, uitamque uiderent, Quam naso secla, aut fletibus apta magis.

O utinam Heraclitus, et hic Democritus essent. Ambo riderent? fleret uterque reor.

[¿Por qué Heráclito se afligió lamentándose de sus tiempos? Porque los crímenes se acumulan sobre crímenes, los males sobre males. ¿Por qué Demócrito rio antaño, riéndose de sus tiempos? Por haber sido manchada con el vicio la virtud. Oh, si vieran ahora las costumbres y la vida de los hombres ¡cuánto más aptos estos siglos para el espíritu burlón o para las lágrimas. ¡Ojalá vivieran ahora Heráclito y Demócrito! ¿Reirían ambos? Creo que uno y otro llorarían.] 
I. 136, Idem.

Fles hominum uitam? Heraclitus luxit abunde. Rides? iam risit omnia Democritus.

Ambo riserunt, flerunt sua secula quondam. Hunc sequeris ridens, hunc sequeris lachrymans.

In lachrymas risum, lachrymasque in gaudia soluis: Fles, rides uitae tempora moesta tuae.

Vita fuit nunquam post condita secula, dicis, Et risu pariter dignior, et lachrymis.

[¿Lloras la vida de los hombres? Ya Heráclito se lamentó en abundancia. ¿Ríes? Ya se rio de todas las cosas Demócrito. Ambos rieron y se lamentaron de sus siglos en otro tiempo. Imitas a uno riendo, al otro llorando. Transformas la risa en lágrimas, las lágrimas en gozos. Lloras y ríes de la época en que te ha tocado vivir. Desde el origen de los tiempos, dices, nunca fue la vida más digna por igual de la risa y de las lágrimas.]

El polígrafo francés Étienne Pasquier (Stephanus Paschasius, 1529-1615), desarrolló el mismo tópico (1723: 1260):

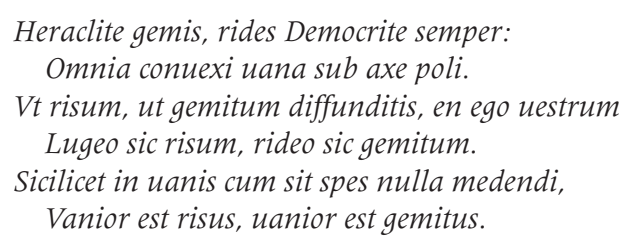

[Te lamentas, Heráclito, y tú, Demócrito, ríes siempre de todas las cosas vanas bajo el cielo. Del mismo modo que derramáis, el uno su risa, el otro sus gemidos, ay, yo deploro vuestra risa y me río del lamento. Naturalmente, al no haber ninguna esperanza de poner remedio en medio de tanta vanidad, más vana es la risa, más vano es el lamento.]

El planteamiento de los epigramas de Interián es, sin embargo, totalmente diferente de las versiones tradicionales. En estas el tratamiento del tema se basa en la aparente paradoja de que ambas visiones del mundo sean equiparables y que en último extremo la concepción radicalmente cómica sea intercambiable con la visión trágica. Interián rechaza, en cambio, ambas posturas, subrayando el peligro moral de la risa y el placer que subyace a la complacencia en la desgracia.

Lo habitual es, por otra parte, que el contraste entre los dos filósofos se plantee en el interior de un mismo poema, mientras que, en este caso, se desarrolla en dos poemas independientes. El tema en las versiones anteriores se inserta todavía en la tradición emblemática; en Interián, en cambio, se incorpora a una tradición ligeramente diferente, la de los retratos. Aunque ambas tengan mucho en común, el planteamiento no es el mismo.

También el epigrama de Interián de Ayala sobre Diógenes mantiene una actitud crítica hacia el personaje (Ribera 1729: 131-132):

Tu quoque percelebrem magna inter lumina mundi Dignus, et indignus quaeris habere locum.

Dignus: quod paruo uiuens pede celsus inanes Delicias hominum, diuitiasque teris.

Cuique rudis baculus tantumdem, ac pera supersunt, Feruidus in luxum perstrepis, imo latras.

Indignus; quod uita parum studiosa pudoris, Non Cynicum, impurum te docet esse canem. 
[Tú también reclamas, digno e indigno de ello, un lugar célebre entre las grandes luminarias del mundo. Digno, porque viviendo con poco, pisoteas los vanos placeres y las riquezas de los hombres. Tú, para quien tu bastón tan solo y tu alforja eran suficientes, gritas -o más bien ladras- colérico contra el lujo; indigno, porque tu vida poco inclinada al pudor pone de manifiesto que no eras un cínico, sino un perro impuro.]

En la caracterización de Diógenes hay un claro eco de la agudeza del epigrama de Marcial sobre el filósofo cínico $(4,53)$, aunque el contexto es totalmente diferente. El verso 8 de Marcial dice: non est hic Cynicus, Cosme: quid ergo? Canis.

El epigrama dedicado por Interián de Ayala a Aristóteles es especial, porque en él el autor rechaza la posición de la filosofía moderna, representada por Descartes y sus seguidores (Ribera, 1729: 130-131):

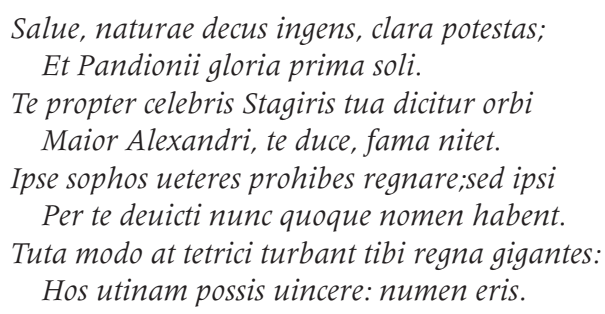

[Salud, honra ingente, clara potencia de la naturaleza y gloria primera de la tierra ateniense. Por tu causa el mundo celebra tu ciudad natal de Estagira, y mayor relumbra la fama de Alejandro por haber sido tú su maestro. Tú impides que dominen los filósofos antiguos, pero los mismos vencidos por ti tienen ahora nombre. Pero tu reino seguro turban ahora tétricos gigantes. ¡Ojalá puedas vencerlos! serás un dios.]

\section{EPIGRAMA Y EMBLEMA}

Los emblemas tienen también una clara presencia en la obra de Interián. Entre las adaptaciones castellanas de textos latinos que cierran la edición de su obra poética se incluyen dos emblemas del propio Alciato. El segundo es el emblema 108, In studiosum captum amore (Ribera, 1729: 180; Alciato, 2016: 118):

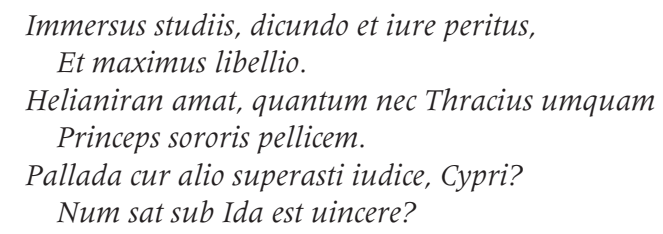

Interián lo traduce así (Ribera, 1729: 180-181):

Celio Jurisconsulto, alumno docto De la enseñanza sabia de Minerva, Entregado las noches y los días $\mathrm{Al}$ afán estudioso de las letras,

A Helianira adora con todo eso (¡Quién en sus años cosa tal creyera!) 


\begin{abstract}
Quanto ni el loco príncipe de Tracia Idolatra a su amada Filomena.

¿Para qué es repetir tantas victorias De hermosa? ¿No bastaba Venus bella El que en el Tribunal de Ida frondoso Lograses decisiva la sentencia? Sin duda que el dictamen, aunque ciego De un viejo enamorado te hace fuerza: Pues con el parecer, bien que entendido De un juez mozo y galán no te contentas.
\end{abstract}

La diferencia de tono y de extensión es llamativa. El texto latino es un típico epigrama. Los cuatro primeros versos presentan el tema, mientras que los versos finales lo comentan, de modo que el discurrir se ajusta totalmente al esquema de la bipartición del epigrama. Por otra parte, esta dualidad reproduce el desdoblamiento genérico entre imagen y epigrama como componentes del emblema. El concepto se basa en poner en relación dos aspectos de la situación (el ser el personaje jurisconsulto y el estar enamorado), cosa que puede hacerse a través de la utilización como código cultural de la mitología. El concepto es frío, pero Interián lo ha transformado en algo totalmente diferente, con la consciencia dolorosa de la ironía de la situación y la identificación con el personaje. Por ridículo que sea nos identificamos con él y el texto se convierte en una especie de elegía sobre el tiempo, la consciencia de los límites humanos, la falta de percepción del propio yo, etc. La dolorosa ironía.

Algunos de los epigramas de Interián están de forma evidente muy próximos a los emblemas, o pueden considerarse como tales. Un ejemplo es el ciclo de cuatro poemas sobre distintos tipos de relojes (Ribera, 1729: 154-156):

Horologium arenae.

Cernis ut humana conclusus ab arte minutim Puluis eat semper, continuoque fluat?

Cernis ut instabiles metitur iugiter horas?

Versus et innumeras itque, reditque uices?

$\mathrm{Ne}$, precor, incautus tenuem mediteris arenam;

Hoc etiam speculum sit tibi, quaeso, uitrum.

Nil nisi mortalem praemonstrat imagine uitam; Vitrum haec et fragile est: puluis et usque fluens.

[¿Ves cuán menudamente corre el polvo, encerrado por arte humana, y fluye sin parar? ¿Ves cómo mide ininterrumpidamente las inestables horas y va y vuelve innumerables veces? No reflexiones a la ligera, por favor, sobre la fina arena. Que este vidrio, te lo ruego, te sirva de espejo. Ninguna otra cosa pone ante tus ojos en imagen sino la vida mortal. Vidrio frágil es esta y polvo que fluye sin parar.]

\title{
Horologium ligneum.
}

Ligna caduca uidens rediuiua cadauera cernis; Machina te tantum mobilis ista docet.

Mortuus ille fuit praecisus ab arbore ramus, Qui modo sollicitis motibus itque redit.

Fabula sit sculptor furatus lumen Olympi: Maius homo diuo lumine numen habet.

Redditus a ligno mortalis, et aethere casus, Ipse tamen ligno uiuere posse, dedit. 
[Cuando ves estos caducos leños percibes la resurrección de los cadáveres. Tanto te muestra esta móvil máquina. Aquella rama muerta, que ahora va y regresa con solícitos movimientos, fue cortada de un árbol. Sea solo un mito la historia del escultor que robó la luz del Olimpo. Mayor numen tiene el hombre por la luz divina. El que se convirtió en mortal por culpa de un árbol, descendido del cielo nos permitió con otro vivir.]

Horologium solare.

Machina quam cernis uitae certissimus index Ipsa tuae est; dubita, si sapis ipse, nihil.

Falleris ah! quisquis fragiles cum duxeris horas, Ipse putes, aliquid lucis habere tuas.

Praetereunt uelut umbra; negas? huc respice, quantas Hic numeras pleno Sole rotante diem?

Ipse equidem número (nec res eget obuia teste)

Non alias, quam quot funebris umbra tegat.

[La máquina que ves es segurísimo índice de tu vida. No lo dudes en absoluto, si eres juicioso. Te engañas tú, quienquiera que, cuando pasas las frágiles horas, creas que las tuyas tienen algo de luz. Pasan como la sombra. ¿Lo niegas? Mira acá, ¿Qué numero cuentas aquí cuando el pleno sol hace girar el día? Yo mismo cuento (es algo obvio que no necesita testigo) no otras que cuantas cubre la fúnebre sombra.]

Horologium cum cantionibus Musicis.

Tempora solicitus labor hic dum praepete cursu Dinumerat, multas itque reditque uices;

Non prius exactas signare fideliter horas

Incipit, et certos reddere ab arte sonos;

Quam circum harmonicos diffundat in aere cantus,

Illius et placidis personet aura modis.

Quid censes? hominum refert ea machina mores,

Et nimium incautis mentibus eloquitur.

Scilicet hae elapsas rident (quid stultius?) horas;

Et, cum fata uident proximiora, canunt.

[Mientras este trabajo cuenta solícito con veloz carrera los tiempos y va y vuelve una y otra vez, no empieza a marcar las horas exactas y a sonar por arte antes de difundir alrededor armoniosos cantos y que el aire resuene con plácidos sones. ¿Qué piensas? Esta máquina refleja las costumbres de los hombres y habla a las mentes incautas. En efecto, estas se ríen de las horas que pasan (¿qué puede haber más estúpido?) y, cuando ven la muerte más cercana, cantan.]

El tema del reloj era frecuente en la literatura de la época. ${ }^{9}$ La conexión del tema con la emblemática se manifiesta en el monumental Mundus symbolicus de Picinelli (1604-c. 1679); en el libro XXI de esta obra, dedicado a los instrumenta mathematica, se desarrolla detenidamente el simbolismo del reloj de sol, del mecánico y del de arena (1678: 584-593; 1687: 182-195).

Todos los epigramas de Interián contienen elementos tradicionales, ligados al tema en la literatura neolatina, especialmente el poema dedicado al reloj solar, en el que se explota la dualidad luz / sombra, y el dedicado al reloj de arena. El mejor comentario a este poema es

9. Sobre el tema del reloj en la literatura neolatina véase Ruiz Sánchez (1998 y 1999).

IMAGO, NÚM. 10, 2018, 217-228 
el párrafo que dedica Filippo Picinelli en su obra al reloj de sol como símbolo de que en el mundo no hay felicidad sin tristeza. ${ }^{10}$

Otro epigrama de Interián titulado Candela lanterna inclusa, ("Candela encerrada en una linterna»), puede considerarse también como un emblema (Ribera, 1729: 164):

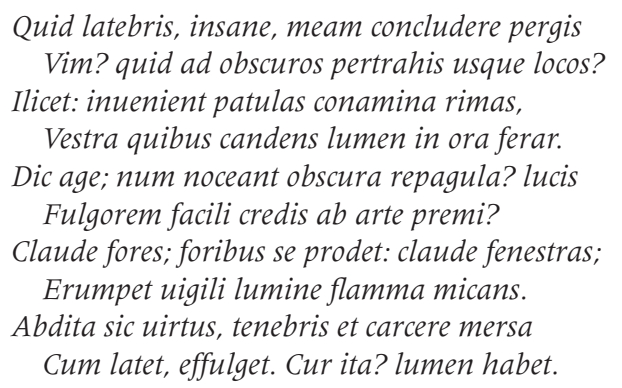

[¿Por qué, loco, te obstinas en encerrar mi poder? ¿Por qué me arrastras continuamente a lugares oscuros? Inútil. Mis esfuerzos encontrarán anchas rendijas, por las cuales como resplandeciente luz llegaré hasta vuestros rostros. Dime. ¿Acaso pueden perjudicarme oscuras barreras? ¿Crees que el esplendor puede ser oprimido mediante fácil artificio? Cierra las puertas, por las puertas se revelará. Cierra las ventanas, la brillante llama con su luz que nunca duerme se abrirá paso. Así la virtud escondida y sumergida en las tinieblas y en un lugar cerrado, mientras está oculta, refulge. ¿Por qué es así? Porque tiene luz.]

El final es una sentencia trillada. Cum latet, effulget es la forma típica de un lema, con el característico cum coincidens y la antítesis semántica (lateo, «estar oculto» vs. effulgeo, «brillar»). Lo mismo ocurre con el final del pentámetro lumen habet. Ambas frases podrían ser perfectamente el lema de un emblema o de una empresa.

Otro ejemplo es el titulado Bombyx, "Gusano de seda» (Ribera, 1729: 165):

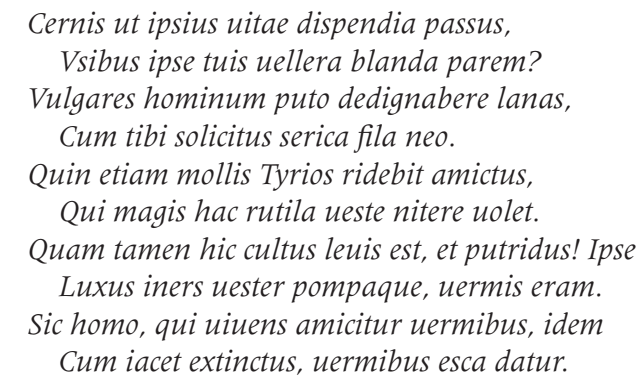

[¿Ves cómo, soportando poner en riesgo mi propia vida, preparo blandos copos de seda para tu beneficio? Desdeñarás, creo, las vulgares lanas de los hombres en comparación con los hilos de seda que yo trenzo solícito para ti. Se reirá incluso de la púrpura tiria quien quiera brillar más con esta rutilante tela. ¡Qué liviano y pútrido es, sin embargo, este ropaje! Yo mismo, que soy ahora para vosotros indolente lujo y magnificencia, era un

10. Che nel mondo non si troui vera felicità mentre al comparir della luce suol gererarsi la mestitia dell'ombre lo dimostra l'horologio da Sole, rimirato da quel pianeta, à cui diedi: SOL GENERAT UMBRAS; il che opera, non da se stesso, mal col mezzo dello stilo: e se il filosofo non volesse aprouare questo moto: certo non potrà negare la verità di quest'altro: DIVIDIT UMBRA DIEM, dimostrando che ciascun giorno, benche chiaro, da qualce diaspacere suol essere adombrato (Picinelli, 1678: 588). 
gusano. Así, el hombre, que mientras vive se viste de gusanos, una vez que yace muerto, es entregado como comida a los gusanos.]

Nuevamente el texto tiene de forma evidente el carácter de emblema. El epigrama explota la ambigüedad del signo: la seda encarna el lujo y también la condición humana perecedera. De acuerdo con la temática de la uanitas, la realidad es el gusano. La vestidura se iguala a la mortaja.

Tampoco está lejos de la iconografía y de lo emblemático un poema como el titulado Nauis Victoria (Ribera, 1729: 158):

Siste parum: hac, hospes, rerum miracula cernis In tabula, quae Oculis exhibet ipsa tuis.

Haec est conuexam terraeque, marisque figuram, Lustrauit uelis quae prior illa ratis.

Quam Ditis uidere domus, Manesque profundi Noctis et aurorae cui patuere uiae.

Ergo huic compositus quid erit, mihi credite, totus Fabula Colchiacus iam nisi uana, labor?

Machina quam instabilis, docuit, sit mundus: ab ipsa Telluris speciem constitit esse globum.

[Detente un momento. En esta imagen, visitante, ves los milagros de la naturaleza, que ella exhibe ante tus ojos. Esta es aquella nave, que la primera recorrió con sus velas la figura esférica de la tierra y del mar. La vieron las moradas de Ditis y los manes abismales y para ella estuvieron abiertos los caminos de la noche y de la aurora. En comparación con ella ¿en qué quedará ya la empresa cólquica, sino en fábula vana? Mostró qué inestable artefacto es el mundo. Por ella tenemos constancia de que la apariencia de la tierra es una esfera.]

Aunque se trate de una circunstancia y de un objeto histórico concreto, el texto contiene elementos emblemáticos. La esfera como símbolo de inestabilidad es convencional en los emblemas.

\section{CONCLUSIÓN}

La utilización de la imagen simbólica como núcleo poético es una característica de la poesía de Interián de Ayala que se observa en todos los géneros cultivados por el autor, aunque se manifiesta especialmente en los epigramas.

La comparación de los ejemplos concretos con sus predecesores demuestra la originalidad con la que autor ha manejado la tradición heredada. En su obra el símbolo escapa de los estrechos límites de la alegoría.

\section{BIBLIOGRAFÍA}

Alciat, A. [2016]. Emblemata / Les Emblèmes, Fac-similé de l'édition lyonnaise Macé Bonhomme de 1551, P. Laurens (trad.), Paris, Les Belles Lettres.

Argelich Gutiérrez, M. ${ }^{a}$ A. [2013]. «Perfil intelectual de Juan Interián de Ayala, autor de El pintor cristiano y erudito", en C. López Calderón y otros (coord.), Barroco iberoamericano: identidades culturales de un imperio, vol. I, 455-464.

IMAGO, NÚM. 10, 2018, 217-228 
Argelich Gutiérrez, M. a A. [2014]. El Pintor cristiano y erudito de Juan Interián de Ayala: entre el moralismo post-tridentino y el racionalismo pre-ilustrado, Universitat de Lleida, Facultat de Lletres. Tesis doctoral.

Bourbon, N. [1533]. Nicolai Borbonii Vandoperani Nugae, Parisiis, apud Michaelem Vascosanum.

Interián de Ayala, J. [1730]. Pictor Christianus eruditus. Siue de erroribus qui passim admittuntur circa pingendas, atque effingendas Sacras Imagines. Madrid, Typographia Conventus praefati Ordinis.

InTERIÁn de Ayala, J. [1782]. El Pintor Christiano y erudito, o tratado de los errores que suelen cometerse frequentemente en pintar, y esculpir las imágenes sagradas (traducción de Luis de Durán y Bastero). Madrid, Joaquín Ibarra.

IRIARTE, J. de [1774]. Obras sueltas de D. Juan de Iriarte, publicadas en obsequio de la literatura, a expensas de varios caballeros amantes del ingenio y del mérito, t. II, Madrid, en la imprenta de D. Francisco Manuel de Mena.

Mestre Sanchis, A. [2002]. "Juan Interián de Ayala, un humanista entre los fundadores de la Real Academia», Bulletin Hispanique, 104.1, 281-302.

Navagero, A. [1973]. Lusus, en A.E. Wilson (ed.), Nieuwkoop, B. de Graaf.

Pasquier, E. [1723]. Iconum Liber en Oeuvres D'Estienne Pasquier, T. I, Amsterdam, aux depens de la Compagnie des Libraires Associez.

PicinelLI, F. [1678]. Mondo simbolico formato d'imprese scelte, spiegate, ed illustrate [...] studiosi diporti dell'abbate D. Filippo Picinelli Milanesi, Venetia, Presso Nicolo Pezzana.

PicinelLi, F. [1687]. Mundus symbolicus in emblematum uniuersitate formatus, explicatus, et tam sacris quam profanis Eruditionibus ac Sententiis illustratus [...]. Idiomate Italico conscriptus a Reuerendissimo Domino, D. Philippo Picinello Medionalensi [...]. Nunc uero Justo Volumine auctus $\theta$ in latinum traductus a R. D. Augustino Erath, T. II, Coloniae Agrippinae, Sumptibus Hermanni Demen.

RiberA, F. de [1729]. Humaniores atque amoeniores ad Musas excursus: siue Opuscula poetica quae quondam lusit aut pinxit R.A.P.M. Fr. Ioannes Interian de Ayala, Matriti, ex Typographia Conventus praefati Ordinis.

Ruiz SÁnchez, M. [1998]. "Los epigramas de G. Amalteo sobre el reloj y las cenizas del enamorado y sus imitaciones en la poesía neolatina», Myrtia, 13, 187-221.

Ruzz SÁnchez, M. [1999]. «El tema del reloj y la angustia del tiempo en dos escritores neolatinos", Myrtia, 14, 187-200.

Ruiz SÁnchez, M. [2013]. "Et erubuit. Simbolismo del color y de la materia en los epigramas neolatinos", $C F C(L), 33.1,73-103$.

http://dx.doi.org/10.5209/rev_CFCL.2013.v33.n1.42759

Ruzz SÁnchez, M. ${ }^{a}$ [2016]. "El tema de la estatua silenciosa: imitación compleja y poesía neolatina», $C F C(L), 36.1,107-119$. http://dx.doi.org/10.5209/rev_CFCL.2016.v36.n1.52546

SAUTEL, P.J. [1665]. Annus sacer poeticus, siue selecta de Diuis Caelitibus epigrammata in singulos anni dies tributa, duobusque tomis partita, 2 vols., Parisiis, apud Ioannem Henault.

SILos, G. [1658]. Musa canicularis siue iconum poeticarum libri III, Romae, apud Godefredum Marcher.

TESAURo, E. [1637]. Emanuelis Thesauri Caesares et ejusdem uaria carmina, Oxonii, Excudebat L. Lichfield impensis Gulielmi Webb bibliopolae.

VisAgIER, J. [1537]. Ioannis Vulteii Remensis Epigrammatum Libri III. eiusdem Xenia, Lugduni, apud Michaelem Parmanterium. 